\title{
3D MODELING OF THE LOBBIA GLACIER BEDROCK (ADAMELLO MASSIF, ITALY) USING GRAVITY AND GPS MEASUREMENTS
}

\author{
A. Rosselli ${ }^{1}$, R. Olivier ${ }^{1}$, E. Tabacco ${ }^{2}$, R. Cefalo ${ }^{3}$, B. Dumont, Ph. Logean, Ph. Rosset ${ }^{1,4}$, \\ M. Manzoni ${ }^{3}$, M. Pavan ${ }^{5}$, S. Urbini ${ }^{5}$ \\ ${ }^{1}$ Institut de Géophysique,Université de Lausanne, C.P., 1015 Lausanne (Switzerland) \\ ${ }^{2}$ Istituto di Geofisica, Università di Milano, Via Cicognara 7, 20129 Milano, (Italy) \\ ${ }^{3}$ Dipartimento di Ingegneria Civile dell'Università degli Studi di Trieste (Italy) \\ ${ }^{4}$ Département de Minéralogie, Université de Genève, 1211 Genève 4 (Switzerland) \\ ${ }^{5}$ Dipartimento di Scienze della Terra, dell'Università di Genova, Viale Benedetto XV 5 , \\ 16132 Genova (Italy)
}

\section{INTRODUCTION}

An important ingredient in establishing climate models for global climatic change studies is the volume of glaciers and its temporal evolution.

Alpine glacier volumes have been calculated for many years from gravity measurements (e.g., Klingelé and Kahle, 1977; Klingelé and al., 1993; Wyss and al, 1995) in Switzerland, Italy, Canada and elsewhere. The accuracy of these determinations can be markedly improved with seismic and radar information useable to constrain the estimated regional gravity effect.

The aims of this study is to improve different geophysical techniques for ice depth and volume investigation on temperate alpine glacier and to give insight into the volume variations of the ice with the time.

During two short periods in 1995 and 1996, the measurements were taken on the upper part of the Lobbia glacier (Adamello Massif, Italy), situated on a plateau at an altitude of $3000 \mathrm{~m}$.and covered an area of about $4 \mathrm{~km}^{2}$ (Fig.1). The surveys were carried out by gravity measurements associated with DGPS positioning, seismic reflection and radar.

The first seismic and radar results from the surveys of 1993 and 1994 gave us a maximum bedrock depth around $180 \mathrm{~m}$ on specific seismic profiles, while radar revealed a transition zone at a depth of $40 \mathrm{~m}$ on all the profiles (Tabacco, Pettinicchio, and Veronese, 1995).

The recent surveys allow to elaborate a 3D model of the bedrock-ice interface. 


\section{METHODOLOGY}

During four days in August 1995, the first gravity survey was carried out coupled with a GPS positioning. The results gave insight into the bedrock geometry and depth in the glacier area but some specific zones were badly unknown (Olivier et al., 1996).

In 1996, the second survey associated with a specific seismic reflection design over the maximum ice depth (Levato et al.,1997, this volume) and some radar profiles was achieved to adjust the gravity modeling.

The positioning part of this survey has been performed by using four double frequency GPS receivers ( two Leica 200 and two Trimble 4000 SSE) in order to overcome problems due to particular relative satellite-receivers configurations which cause divergence in the solution, with high RDOP (Relative Dilution of Precision) parameter values.

Stop \& Go, Fast Static and Interferential Cinematic techniques were performed to delimit the bedrock outcrop and cover the whole glacier area.

Geographic reference uses the WGS84 system calculated by linking the topographic network to a point at Tonale Pass from the local IGMI95 network. The 3D transformations to the WGS84 coordinates of all the static and cinematic surveys have been performed using the parameters furnished by the technical local cartography and two trigonometric control points.

The topographic map of the figure 1 presents the level curves obtained with an inverse square distance grid interpolation method and the position of the recorded points.

For the gravity part of the survey, more than 250 stations along 18 profiles are measured using three gravity crews (L\&R meters) and one profile setting crew (Wild TC 600).

The density of the Bouguer model (Fig. 2) is chosen as $2.72 \mathrm{~g} / \mathrm{cm}^{3}$ corresponding to the density of the Adamello granite and the mean quadratic final error of the Bouguer anomalies is around $0.25 \mathrm{mGals}$.

Gravity terrain correction was calculated up to $166 \mathrm{~km}$ and in a perimeter of $1 \mathrm{to} 2 \mathrm{~km}$ apart of the area border, 10 gravity stations were measured using an helicopter to improve the regional anomaly trend. The Regional Anomaly was adjusted from the results of seismic and radar as far as possible.

The positioning precision is around $10 \mathrm{~cm}$ and the gravity measurement one around $0.2 \mathrm{mGals}$ which is quite good relative to the difficult fieldwork environment.

The high coherence of the derived residual (Fig. 3) allows to map the granite basement.

\section{D MODELING}

In order to take into account the three-dimensional gravity effect of the ice masses and to obtain the best resolution of the geometry of the glacier, we have used the LCT modeling software $\operatorname{Mod} 2 \mathrm{D}^{\circ}$ and $\operatorname{Mod} 3 \mathrm{D}^{\circ}$ to create a geometric model and calculate the gravity response.

A structural section is associated to each profile basing on the hypothesis that the residual gravity anomaly is the representation of the superficial gravity effects induced only by the presence of the ice. We used an average ice density value of $0.92 \mathrm{~g} / \mathrm{cm}^{3}$, according to the literature, and a mean granite density value estimated as $2.72 \mathrm{~g} / \mathrm{cm}^{3}$, according to the sampling measurements. 
The gravity effect of the geometric model is calculated for each measured point and compared to the local gravity effect of the residual anomaly.

The difference between these two effects is minimized by applying successive iterative corrections to the geometry of the model, and thus obtain a possible shape for the granite substratum (fig.4)

\section{CONCLUSION}

This integrated study gives informations on ice thickness and geometric characteristics on a temperate alpine glacier.

It combines the three geophysics investigations which are seismic reflection, radar and particularly gravity measurements associated with DGPS positioning.

In few days of survey, it is possible to have a good knowledge of the ice volume and with periodic measurements to be able to estimate the ice volume variations of different temperate glaciers. At the alpine arc level, the temporal evolution should give new quantitative elements for the climatic change model for the Alps.

\section{REFERENCES AND BIBLIOGRAPHY}

Klingelé E. et Khale H.G. (1977). Gravity profiling as a technique for determining the thichness of glacier ice. Pure and Applied Geophysics, vol. 115, 989-998.

Klingelé E., Olivier R. (1980). La Nouvelle Carte des Anomalies de Bouguer de la Suisse. Mat. Géol. Suisse, Série Géophysique, $n^{\circ} 20,57$ pages.

Klingelé E. et Vonder Mühl D. (1993). Gravimetrische Untersuchungen im Permafrost des Blockgletschers Murtel-Corvatsch (Oberengadin). Vermessung, Photogrammetrie, Kulturtechnick; 10/93, 575-580.

L. Levato, L. Veronese, A. Lozej, E. Santuliana, et E. Tabacco (1997). A seismic reflection survey to help determine the ice thickness on the Lobbia glacier, Adamello massif, Italy, (extended abstract, this volume).

R. Olivier, A. Rosselli, Ph. Logean, B. Dumont, A. Re, Ph. Rosset, E. Tabacco, N. Tosi, L. Veronese, E. Santuliana, G. Manzoni, et R. Cefalo. (1996). Ice depth determination by gravity measurements on the Lobbia glacier (Adamello massif, Italy). Book of abstracts of the International Congress on Environment/Climate, ICEC-96, march 4-8, 1996, Rome, Italy, p. 163 (abstract).

E. Tabacco, P. Pettinicchio, and L. Veronese, 1995. Radar and seismic survey on temperate glaciers in northern Italy, Adamello and Stelvio Glacier. Proceedings of the EEGS 1st Meeting, September, 25-27th, 1995, Torino, Italy, p.190-197 (extended abstract).

Vonder Mühl D., et Klingelé E. (1994). Gravimetrical Investigation of Ice-Rich Permafrost within the Rock Glacier Murtel-Corvatsch (Upper Engadin, Swiss Alps). Permafrost and Perglacial Process, vol.5, 13-24.

Wyss T.M., Klingelé E. et Kääb A. (1995). Gravimetric Investigations in the influence area of the Unteraar glacier (Switzerland). Institut of Geodesy and Photogrammetry, Swiss Federal Institute of Technology, Zürich, report n ${ }^{\circ} 243,59 \mathrm{pp}$.

LCT2D Software (1992). LCT Inc., Houston. 


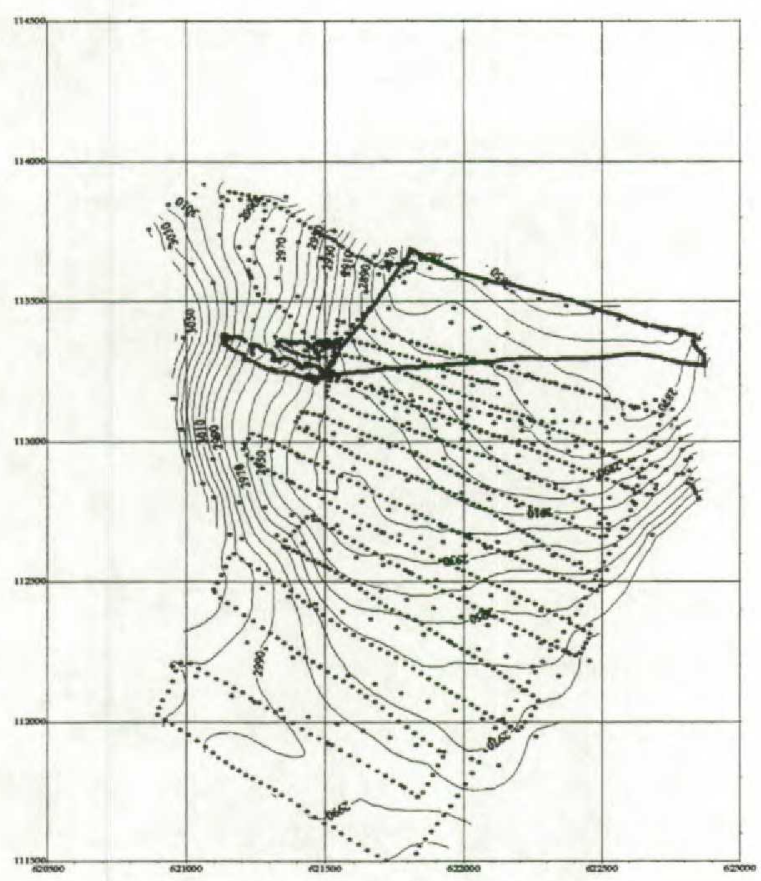

FIG. 1 : GPS Topographic Map (survey 1995 and 1996)

- : GPS stations

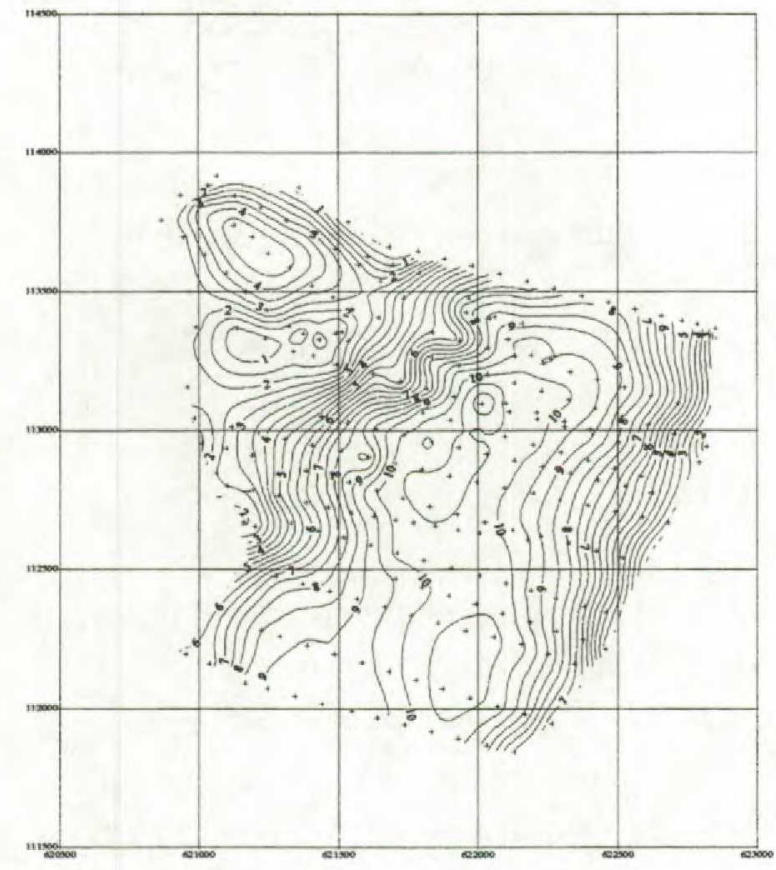

FIG. 3 : Residual Anomaly Map (survey 1995 and 1996)

- : gravity stations

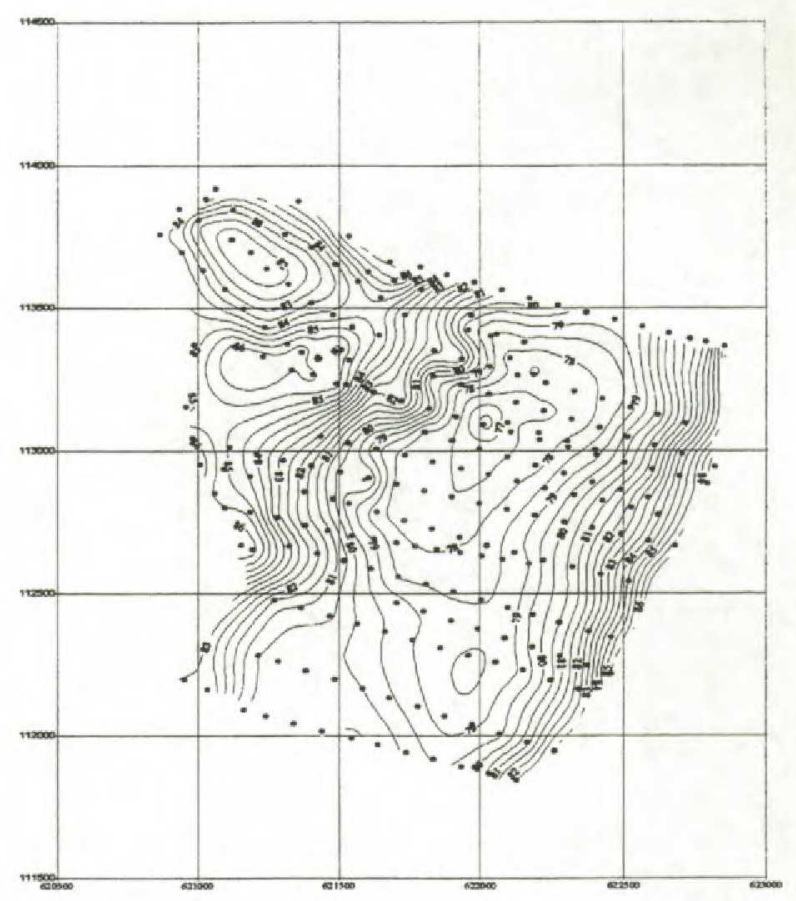

FIG. 2 : Bouguer Anomaly Map $\rho=2.72 \mathrm{~g} / \mathrm{cm}^{3}$ (survey 1995 and 1996)

- : gravity stations

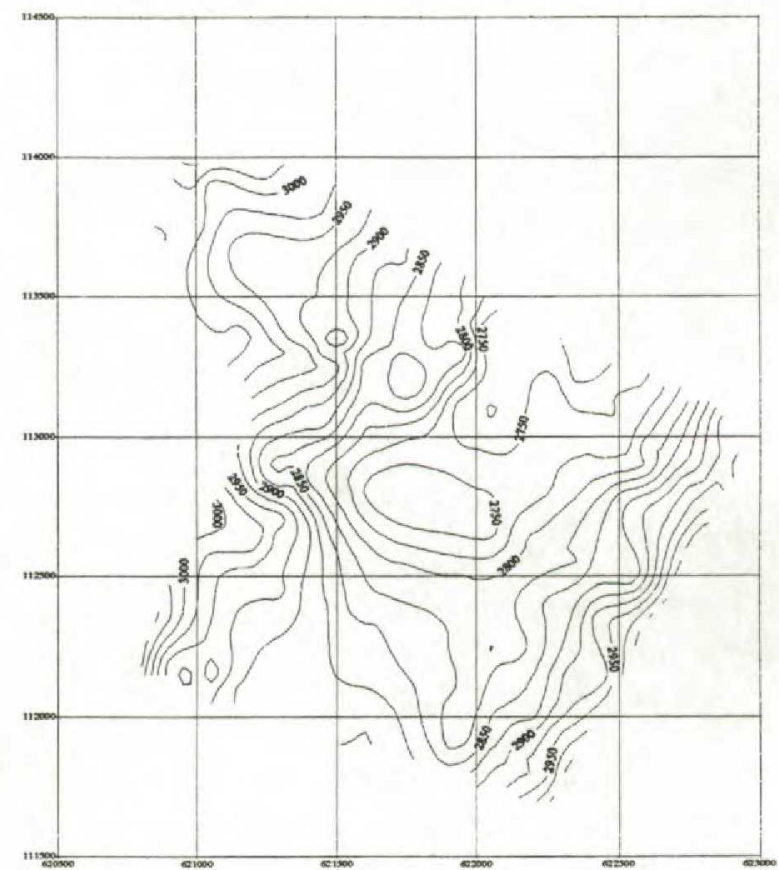

FIG. 4 : Preliminary granite substratum Map (survey 1995) 